\title{
GENDER, RESOURCES ACROSS THE LIFE COURSE, AND COGNITIVE FUNCTIONING IN EGYPT*
}

\author{
KATHRYN M. YOUNT
}

\begin{abstract}
In this article, I evaluate the life-course determinants of cognitive functioning among 1,003 women and men aged 50 and older in Ismailia, Egypt. Three questions motivate this analysis: (1) Do older women have poorer cognitive functioning than do older men?; (2) Do cognitive resources accrued in childhood and adulthood have net positive associations with later-life cognitive functioning for women and men?; and (3) To what extent do differences in the amounts and effects of women's and men's cognitive resources account for gaps in their cognitive functioning? Compared with men, women have lower Modified-Mini Mental Status Exam (M-MMSE) scores for overall cognitive functioning. Cognitive resources in childhood and adulthood are jointly associated with the M-MMSE score. About $83 \%$ of the gender gap in mean M-MMSE scores is attributable to gaps in men's and women's attributes across the life course. Gender gaps in childhood cognitive resources-and especially schooling attainment-account for the largest share (18\%) of the residual gender gap in cognitive functioning.
\end{abstract}

referential investments in the human resources of boys have been common to many resource-poor settings (King and Mason 2001; Lloyd 2005), and the effects of such investments on gender gaps in child health are known (e.g., Hill and Upchurch 1995). Less well known is the extent to which gender gaps in resources that are accrued across the life course account for gender gaps in later-life health, despite known gender differences in the risks of illness, disability, and death. Demographic research on later-life health also has focused on physical conditions, even though dementia and neuropsychiatric disorders account for a large $(\sim 3 \%)$ and growing share of the disease burden worldwide (World Health Organization [WHO] 2007).

This article assesses the determinants of cognitive functioning among older women and men (e.g., those aged 50 and older) in Ismailia, Egypt. It explores whether and to what extent (1) women have poorer cognitive functioning than men, (2) cognitive resources in childhood and adulthood have net positive associations with cognitive functioning for women and men, and (3) differences in the amounts and effects of women's and men's cognitive resources account for differences in their cognitive functioning. Egypt is a superb setting in which to conduct this work because of long-standing gender gaps in opportunities across the life course (e.g., Yount 2001; Yount and Sibai forthcoming) and poor knowledge about their potential effects on later-life cognitive functioning.

\section{COGNITIVE RESOURCES ACROSS THE LIFE COURSE AND COGNITIVE AGING}

Research on cognitive aging reveals a strong association between increasing age and the onset of neuropathology and cognitive decline, especially after age 60; the pace of agerelated cognitive decline, however, can vary within and across age cohorts (e.g., Schaie 1994; Zhang et al. 1990; Zhou et al. 2006). Gerontologists have coined the term reserve

\footnotetext{
*Kathryn M. Yount, Hubert Department of Global Health and Department of Sociology, Emory University, 1518 Clifton Road NE, Room 724, Atlanta, GA 30322; e-mail:kyount@sph.emory.edu. This research was supported by grants from the National Institute on Aging (1 R03-AG021707-01; PI: Kathryn M. Yount), the Social Research Center, American University in Cairo (Co-Investigator: Zeinab Khadr), and the University Research Committee at Emory University. Assistance from Drs. Emily Agree and Aryeh Stein in designing the study, and from Dr. Hoda Rashad in its execution, are valued. Dr. Nadia El-Afify's role in training staff to conduct the in-home tests of physical performance also is appreciated. Dr. Yount also wishes to thank Gender Economics for Research and Policy Analysis (GERPA) for their support in this research.
} 
to explain variation in age-related levels and trajectories of cognitive decline (Stern et al. 1992).

Reserve refers to aspects of brain structure and function that can delay the clinical effects of neuropathology. Structural reserve refers to the protective potential of anatomical features of the brain, such as its size, neural density, and synaptic connectivity. Functional reserve refers to the brain's processing capacity, or efficiency of its neural network. Following Figure 1, reserve (a) is best represented by peak, premorbid cognitive ability (b), which modifies the expression - in terms of cognitive impairment (c) - of damage to the central nervous system (d). Thus, reserve protects against the functional consequences of neuropathology by delaying its detection rather than by preventing its acquisition (Bornstein, Copenhaver, and Mortimer 2006; Richards and Deary 2005). Reserve has genetic, uterine, and early postnatal determinants but theoretically can be augmented across the life course (Figure 1) (e.g., Bornstein et al. 2006; Richards and Deary 2005). Cognitive resources - or sources of mental stimulation in childhood (e) and adulthood (f) - thus may affect a person's reserve (Everson-Rose et al. 2003; Turrell et al. 2002). Important cognitive resources in childhood include the family's socioeconomic status (e.g., Turrell et al. 2002; Wilson et al. 2005) and investments in schooling (e.g., Albert 1995; Cagney and Lauderdale 2002; Richards and Sacker 2003; Zhang et al. 1990). Notably, childhood health and nutrition may have confounding effects if micronutrient intakes also alter brain development (Albert 1995). Key cognitive resources in adulthood include one's socioeconomic environment, occupational complexity (e.g., Richards and Sacker 2003), and physical and social activities (e.g., Scarmeas and Stern 2003).

A person's cognitive resources in childhood and adulthood may also indirectly affect his or her reserve (Figure 1). These potential pathways are multiple and complex, but three examples are illustrative. First, a person's schooling attainment (e) may improve his or her occupational trajectory (f) (e.g., Richards and Sacker 2003). Second, some occupational exposures (f) may increase the risk of central nervous system damage (d), affecting a person's brain size and function (a) (Park et al. 2005). Third, a poor socioeconomic setting in childhood, low schooling attainment, or adverse occupational exposures may trigger behaviors (e.g., sedentary lifestyle, poor diet, or smoking) or conditions (e.g., cardiovascular disease and diabetes) that are risks for cognitive impairment (e.g., Breteler et al. 1994; Cerhan et al. 1998; Kuusisto et al. 1993; Richards et al. 2003). Given such pathways, the point is that mental stimulation associated with critical cognitive resources may independently affect an older adult's cognitive functioning.

\section{GENDER GAPS IN COGNITIVE AGING}

Among several life-course studies of cognitive functioning, few have measured and accounted for gender gaps therein (an exception is Zhang et al. [1990]). Such gaps may result from sex-linked differences in health-related risks and biological vulnerabilities (e.g., Kannel 2002; Lebrun et al. 2005). Yet, among older adults in the Swedish Twin Registry, heritable influences explained only $35 \%$ of the variation in cognitive dysfunction, and differences across women and men were not significant (Reynolds et al. 2006). Thus, a lifecourse model of gender gaps in cognitive resources may help to account for gender gaps in cognitive functioning.

Research in this area is essential for several reasons. First, women make up a majority of aging populations globally (UN 2007), and dementias and neuropsychiatric disorders compose a large $(\sim 3 \%)$ and growing share of the global disease burden (WHO 2007). Second, female deficits in cognitive functioning are documented in some poor countries (e.g., Hsu 2005; Zhang 2006), and gender gaps in cognitive resources - such as schooling, occupation, and social networks - have been common (Lloyd 2005).

The latter three gender gaps prevail in several Arab countries. In several countries (Egypt, Jordan, Lebanon, Morocco, Tunisia, and Yemen), relatively more older men (those 

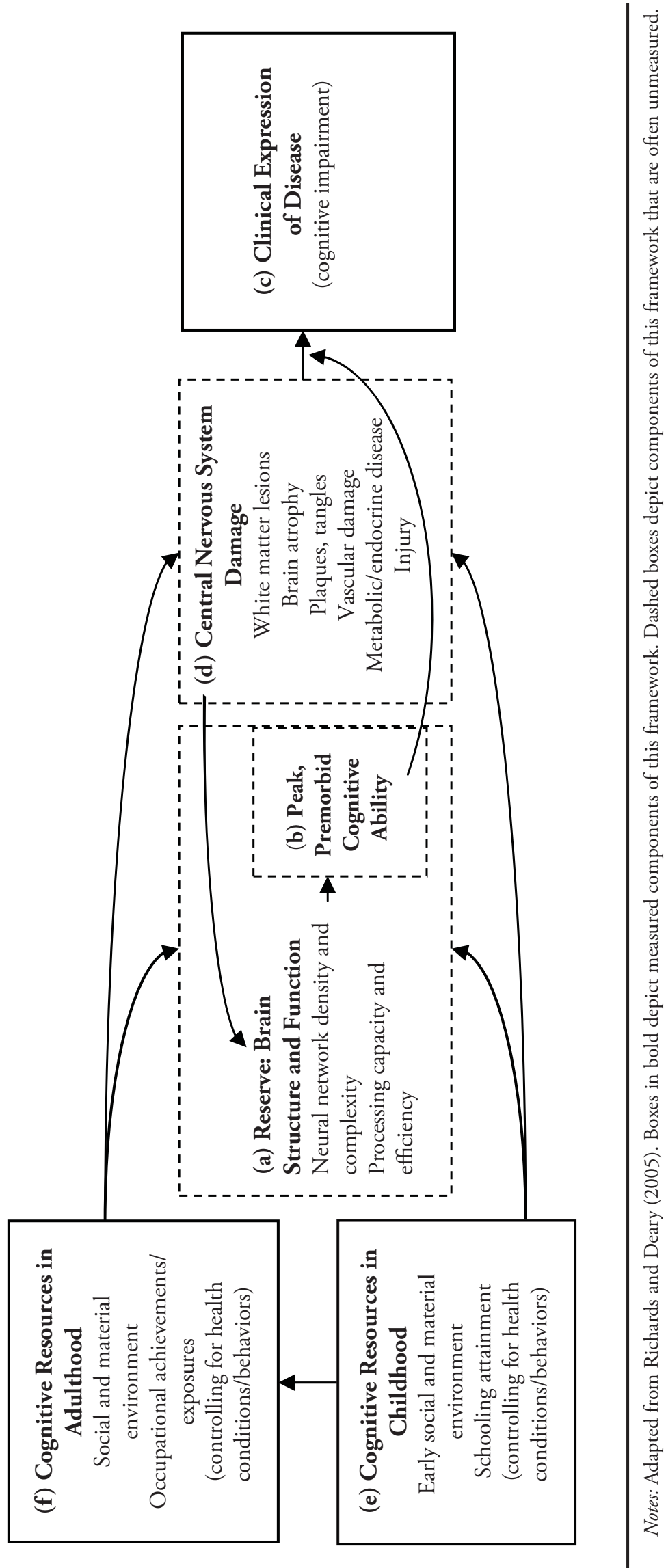
aged 50 or older) than women have ever attended school (Yount and Sibai forthcoming). Also, Arab women less often ever enter the formal labor market (World Bank Group 2002), ${ }^{1}$ and more often stop working at the time of marriage (El-Zanaty et al. 1996). Lastly, social restrictions on women's mobility (El-Zanaty et al. 1996) and their heavy investments in kin-keeping (Yount and Sibai forthcoming) may diminish their social-network size.

Another reason for gender gaps in cognitive functioning is that qualitative differences in men's and women's cognitive resources may exacerbate differences in their mental stimulation. The familial environment is one example. In settings where parents rely financially upon sons for old-age support, poor parents may invest more time and money in their sons, whereas wealthier parents may share their resources more equitably (e.g., Rosenzweig and Schultz 1982). School is another example. Boys and girls may be socialized to pursue different studies (e.g., home economics for girls) and to value education for different ends (e.g., marriage for girls; career for boys) (El-Zanaty et al. 1996; Lloyd 2005). In settings like Egypt, boys and girls may even study in gender-segregated classrooms. Still, girls in some settings may apply themselves more intently, accruing more mental stimulation per grade of schooling (e.g., Alderman et al. 1996) and outperforming boys in some subjects in Egypt and elsewhere (Lloyd 2005). These gender gaps in the quality of schooling may exacerbate gaps in occupational trajectories (Lloyd 2005) such that women more often never work, exit the workforce, or work in selected sectors (Yount and Sibai forthcoming).

These gendered life-course experiences are better documented than are their possible implications for cognitive functioning. Yet, existing studies suggest that some cognitive resources have gender-differentiated effects. In China, Great Britain, Pakistan, and the United States, literacy and schooling have been more positively associated with cognitive functioning for women (Alderman et al. 1996; Luo and Waite 2005; Manly et al. 2005; Zhou et al. 2006); in Britain, occupation has been more positively associated with cognitive functioning for men (Richards and Sacker 2003). In older Swedish men, contact with children has been negatively associated with symptoms including impaired concentration (Rennemark and Hagberg 1999).

Two conclusions emerge from this discussion. First, research on the life-course determinants of cognitive functioning is lacking for poorer settings, and the applicability of studies in wealthier contexts is uncertain. Second, gender gaps in cognitive functioning are understudied, especially in poor, highly gender-stratified settings. These conclusions motivate three hypotheses about cognitive functioning among older Egyptian women and men:

Hypothesis 1: Compared with older men, older women will have poorer cognitive functioning.

Hypothesis 2: For women and men, cognitive resources in both childhood and adulthood will have net positive associations with later-life cognitive functioning.

Hypothesis 3: Women's poorer later-life cognitive functioning may be attributable to

(a) their lower levels of cognitive resources in childhood and adulthood, and

(b) the gender-differentiated effects of these cognitive resources.

\section{SETTING}

In 2005, Egypt's population of nearly 73 million includes about 7.6 million adults aged 55 years or older. About 15 million people, or $15 \%$ of the projected population, should be that age by 2025 . Women, on average, live longer than men (74 vs. 69 years), so a

1. Labor force statistics may miss women's productive household contributions (Hoodfar 1997). 
majority (53\%) of Egyptians aged 55 or older are women. Older Egyptians experience considerable disability (e.g., Yount and Agree 2005) and morbidities underlying cognitive impairment (e.g., Galal 2002; Herman et al. 1995; Ibrahim et al. 2001). Such conditions are more common in Egyptian women, so healthy life expectancy is lower for women than men (UNDP 2002).

Ismailia governorate is located in Lower (or Northern) Egypt. In 2000/2001, the real gross domestic product (GDP) per capita and rate of adult ( $\geq 15$ years) literacy were higher in Ismailia than in all Lower Egypt (5,474 vs. 4,623 in PPP\$; 73\% vs. 65\%). Also, rates of literacy (64\% vs. 53\%) and workforce participation (17\% vs. 16\%) are higher for Ismailian than Lower Egyptian women, but these rates for Islmailian women are only $71 \%$ and $21 \%$, respectively, of those for Ismailian men. ${ }^{2}$

\section{SAMPLE AND DATA}

To generate the sample frame, a household census was conducted in 11 primary sampling units selected with probability proportional to size in one rural and one urban district in the Ismailia governorate. An age-gender stratified sample of 1,182 adults 50 years and older was selected, of whom 1,053 (89\%; 491 men, 562 women) completed a baseline interview. (See Yount and Khadr [2006] for further details.) Some men (16) and women (36) who scored less than 11 on the M-MMSE identified a person to respond on their behalf. All respondents reported on their social, economic, and health conditions during the first 15 years of life; schooling, marital, and occupational histories; dates of diagnosis of chronic and acute illnesses; risk behaviors; and illness-specific medical care and medications. This analysis includes 995 older adults (466 men, 529 women), ${ }^{3}$ for a weighted sample of 1,003 (500 men, 503 women). ${ }^{4}$

The outcome $Y_{i}$ is a $0-20$ score for cognitive performance, which is based on the sum of scores for items included in the M-MMSE. The original MMSE, or adaptations of it, have been used in clinical- and population-based research in Egypt (e.g., Farrag et al. 2002) and elsewhere (e.g., Elhan et al. 2005; Escobar et al. 1986) to test for cognitive impairment and to screen for dementia. The exam assesses orientation, registration, attention and calculation, recall, and language. One problem with using the original MMSE in poor settings is that literacy is required to complete the exam. Some adaptations of the MMSE, however, have been valid and reliable for illiterate populations (e.g., Kabir and Herlitz 2000). The M-MMSE in this study has been used in other cross-cultural studies of older adults (Palloni n.d.), does not require literacy, and tests a subset of items capturing all subdomains (form available upon request). ${ }^{5}$ The average correlation among items for this scale exceeds .3 , and the summative score is reliable (Chronbach's $\alpha=.77$ for women and .78 for men) ${ }^{6}$

Measures for cognitive resources and constraints in childhood $\left(\mathbf{C}_{\mathbf{r}}\right)$ capture important sources of, or barriers to, mental stimulation from birth through age 15 years. This period of the life course was selected to reflect childhood because it corresponds to ones used in other cross-cultural studies of older adults (e.g., Palloni n.d.), and because the legal age at marriage for females is 16 years in Egypt. Such resources and constraints (italicized) include the respondent's father's schooling (none, any, missing), whether the respondent

2. Unless indicated, figures in this paragraph come from the United Nations Development Programme (UNDP) and Institute for National Planning (INP) (2003).

3. This sample excludes 129 nonparticipants at baseline, 25 participants with missing M-MMSE scores, and 33 participants with missing data on covariates with fewer than 10 missing responses.

4. Weights were calculated by using the inverse of the sampling fractions so that the age-sex distribution of the sample for each district conformed to that of the population aged 50 years and older in each district, by fiveyear age groups and sex, according to the 1996 census.

5. The retained questions in the M-MMSE have equivalent counterparts in the original MMSE. The main departure of the M-MMSE is that the original questions requiring literacy are removed. Thus, respondents' scores on the M-MMSE are likely to be a comparable subscale of the MMSE.

6. Cronbach's alpha is computed using standardized scores (mean $=0 ; S D=1)$ for each item. 
lived at least five years in a rural area (yes, no, missing), the respondent's self-rated family economic status relative to others (very poor $=1$, poor $=2$, average $=3$, good $=4$, very good $=5$ ), and grades of schooling and grades of schooling squared to permit nonlinear associations between schooling and cognitive functioning. Common barriers to schooling, and thus cognitive constraints in this setting, include early first marriage (before age 16) and child labor (work for cash or kind before age 16). ${ }^{7,8}$

Measures for cognitive resources and constraints in adulthood $\left(\mathbf{A}_{\mathbf{r}}\right)$ capture important sources of, and barriers to, mental stimulation after age $15 .{ }^{9}$ Such resources and constraints (italicized) include the respondent's work status at age 50 years (yes, no); a $0-17$ score for household standard of living (the sum of seventeen $0-1$ indicators for the ownership or presence of household assets or amenities); and measures for family networks and social integration, including the respondent's number of children ever born, number of deceased sons and daughters, number of living brothers and sisters, living arrangements five years before the interview (alone, other), relational status of the first spouse (cousin, other blood relative, other),${ }^{10}$ and any experience of widowhood or divorce (yes, no).

Controls for health status and risk behaviors in childhood $\left(\mathbf{C}_{h}\right)$ include the respondent's confinement to bed for at least one month (yes, no, missing); reported initiation of smoking (no, yes, missing); and whether the respondent reported any of several illnesses (yes, no): bilharizia, anemia, nephritis, hepatitis, measles, tuberculosis, rheumatic fever, asthma, chronic bronchitis, polio, mumps, meningitis, and other illnesses. Controls for health status and risk behaviors in adulthood $\left(\mathbf{A}_{h}\right)$ include reported conditions that predict later-life cognitive functioning, including doctor-diagnosed stroke, heart disease, and diabetes (yes, no); risk markers for these diseases (hypertension: yes, no, missing); and a $0-8$ score for using medications in the prior year to manage the preceding four conditions $(0=$ took no medications, 1 = took but stopped, 2 = took continuously). Other control variables $(\mathbf{X})$ include the respondent's age in years and the district in which the respondent was living at interview (rural, urban). Other measures of cognitive resources in childhood and adulthood were considered but lacked sufficient variability to be included. ${ }^{11}$

\section{ANALYTIC STRATEGY}

To assess Hypothesis 1, regarding male-female differences in cognitive functioning, women's and men's mean and median scores of the M-MMSE and its subdomains were compared, overall and by age $(50-59,60-69, \geq 70$ years). Differences in the attributes of women and men were tested using chi-squared tests. Sample weights and robust variance estimators were used to adjust for the age- and gender-stratified cluster sample design (Huber 1967; White 1980).

7. Age at first marriage was not reported by $9 \%$ of men and $21 \%$ of women. These ages were imputed using OLS regression and the respondent's age, gender, paternal schooling, childhood residence, and birth place (Ismailia, other governorate) as predictors $\left(R^{2}=.3\right)$. An indicator for whether the respondent's age at first marriage was imputed also is included.

8. One could argue that early marriage and child labor provide mental stimulation in terms of social support and exposure to the work force. In this generation, however, child labor would largely have been agricultural and/or unskilled, and such work in adulthood is not associated with better cognitive functioning. Also, the mobility of young married women tends to be more restricted than that of older married women in Egypt (El-Zanaty et al. 1996). Thus, early marriage may curtail certain social interactions for a young woman.

9. There is some difficulty in interpreting the effects of cognitive resources in adulthood on cognitive functioning because the causality can go in both directions.

10. Marrying a blood relative is considered a cognitive constraint because it implies greater parental control over marriage, and narrower pre- and postmarital social networks.

11. These measures included whether the respondent's father and mother were deceased, maternal schooling, and occupational status at age 50 years. Regarding occupation, most women (83\%) were not working at age 50 , and those who were working were concentrated in few occupations. Thus, the largest gender gap regarding work and mental stimulation in this setting is whether women were working for cash or kind at age 50. 
Using separate samples for women and men, multivariate ordinary least squares (OLS) models were fitted to evaluate the significance of net associations of $\mathbf{C}_{\mathbf{r}}$ and $\mathbf{A}_{\mathbf{r}}$ with $Y_{i}$ (Hypothesis 2):

$$
Y_{i}=\beta_{0 G}+\beta_{X G} \mathbf{X}+\beta_{C_{r} G} \mathbf{C}_{\mathbf{r}}+\beta_{C_{h} G} \mathbf{C}_{\mathbf{h}}+\beta_{A_{r} G} \mathbf{A}_{\mathbf{r}}+\beta_{A_{h} G} \mathbf{A}_{\mathbf{h}}+e_{i}
$$

where $G$ indicates gender. Standard diagnostics were used to assess model fits. ${ }^{12}$ To evaluate Hypothesis 3 b, concerning gender gaps in the net associations of $\mathbf{C}_{\mathbf{r}}$ and $\mathbf{A}_{\mathbf{r}}$, adjusted Wald $F$ statistics with Bonferroni corrections for multiple comparisons were computed to test for differences across gender in each coefficient vector. Similar tests were performed for the coefficient vectors for $\mathbf{C}_{h}, \mathbf{A}_{h}$, and $\mathbf{X}$. To assess which coefficients differed across gender, Wald $F$ tests with Bonferroni corrections were computed for individual coefficients.

Oaxaca-Blinder decomposition methods were used to evaluate further Hypotheses $3 \mathrm{a}$ and $3 \mathrm{~b}$. Observed gender differences in mean M-MMSE scores may reflect differences in (a) the cognitive resources accrued by men and women, (b) the effects of those resources, or (c) a combination of the two. Define women's and men's mean outcomes as $Y_{W}$ and $Y_{M}$; $\mathbf{Z}_{\mathbf{W}}$ and $\mathbf{Z}_{\mathbf{M}}$ as row vectors of mean values for men and women of observed elements in $\mathbf{C}_{\mathrm{r}}, \mathbf{C}_{\mathrm{h}}, \mathbf{A}_{\mathrm{r}}, \mathbf{A}_{\mathrm{h}}$, and $\mathbf{X}$; and $\boldsymbol{\beta}_{\mathbf{W}}$ and $\boldsymbol{\beta}_{\mathbf{M}}$ as vectors containing all parameter estimates found in (1), estimated separately for women and men. The Oaxaca-Blinder decomposition can be written as follows:

$$
Y_{M}-Y_{W}=\mathbf{a}_{\mathbf{M}}\left(\mathbf{Z}_{\mathbf{M}}-\mathbf{Z}_{\mathbf{W}}\right)+\mathbf{Z}_{\mathbf{W}}\left(\boldsymbol{\beta}_{\mathbf{M}}-\boldsymbol{\beta}_{\mathbf{W}}\right) .
$$

Here, the difference in mean M-MMSE scores for men and women is disaggregated into two parts: that attributable to differences in mean outcome-generating characteristics, and that attributable to differences in their effects. ${ }^{13}$ There is an index problem associated with Eq. (2), however. Namely, the first term is based on the estimates of cognitive functioning that would be observed if a woman received male effects to her attributes; yet, Eq. (2) could be expressed as the score that a man would obtain if he experienced female effects. To address this problem, Eq. (2) is computed using a weighting matrix proposed by Neumark (1988) and Oaxaca and Ransom (1994). The standard errors for each component are computed using a method proposed by Jann (2005). The Oaxaca-Blinder decomposition complements the preceding multivariate analyses by summarizing the percentages of the male-female gap in mean M-MMSE scores that are attributable to gender differences in mean attributes, and in their effects.

Notably, the covariates in this analysis are based on retrospective reports, which are subject to recall bias. Poor reliability may attenuate estimated regression coefficients, and the nature and extent of these biases across gender are unknown. In this study, selected baseline questions were asked again in a follow-up interview. Chance-corrected agreement (Kappa) for reported attributes of childhood (e.g., birthplace; 0.8) are higher than are those for reported behaviors in childhood (e.g., smoking and work; 0.4-0.5), and Kappas for reported attributes in adulthood (0.6-0.9) are higher than are those for reported attributes in childhood (0.4-0.8). Kappas vary positively with baseline M-MMSE scores but differ little

12. The M-MMSE score is left skewed, and 11 scores are severe outliers $(<2)$. These participants are mainly women (7) aged 77 years or older (10) with no schooling (9) who scored in the lowest 25 th percentile (8) on a proxy's assessment of their cognitive functioning and ability to perform activities of daily living. The coefficients based on OLS regressions using the samples of women and men that include and exclude these outliers do not differ significantly. The inferences based on OLS regressions of a transformed M-MMSE score ( $\ln (-\mathrm{M}-\mathrm{MMSE}$ $+24.70353)$ ) that eliminates skewness do not differ from those based on OLS regressions of the nontransformed score.

13. Some means from the Oaxaca-Blinder decomposition may be endogenous (e.g., schooling, age at marriage), but any biases in the coefficients likely cancel out in the comparison across gender. 
by gender. Reestimation of Eq. (1) for women and men with test-retest data, using OLS regression and generalized linear models for measurement error data (Cook and Stefanski 1994), showed that inferences were consistent for most covariates $(>83 \%)$. (Results are available upon request.)

Possible selection biases attributable to nonparticipation at baseline, item nonresponse, and differential survival also are notable. First, census-enumerated participants and nonparticipants at baseline do not differ in gender, schooling, or household standard of living. However, on average, participants were older and more often were widowed and not working. These differences appeared among women and men, so observed gender gaps in cognitive functioning should be unbiased if their reasons for nonparticipation were similar. Second, Eq. (1) was reestimated for several samples in which covariate nonresponses were excluded or were imputed using various methods. Most covariates had less than $2 \%$ of values missing, and estimated coefficients generally were consistent across samples. The presented results are based on the sample in which missing values for age at first marriage are imputed using regression imputation and flagged, and missing values for categorical variables having at least 10 missing responses are coded as such (father's schooling; rural residence for 5 or more years, smoking, and bed confinement for at least one month before age 16; smoking after age 15; doctor-diagnosed high blood pressure). Third, variation in the age-specific survival probabilities for women and men may relate to their cognitive functioning, biasing observed gender gaps (e.g., Perls et al. 1993). Sampling weights were adjusted by using age- and gender-specific survival probabilities estimated from 1960 and 1976 mortality rates. Such adjustments modestly reduced gender gaps in the M-MMSE score and altered little the coefficients and inferences for other covariates. (Results are available upon request.)

\section{RESULTS}

According to Table 1, women have significantly lower mean (15.2 vs. 17.2) and median (15.0 vs. 17.0) scores for the M-MMSE, and the difference in mean M-MMSE scores (women - men) varies modestly across age group ( -2.2 among 50 - to 59-year-olds; -1.9 among those aged 60-69). Women's deficit in their total M-MMSE score is attributable to deficits in their mean subscores for orientation, attention/calculation, and language. For the 0-4 measure of orientation, women's deficit varies modestly across age, from -0.2 among 50- to 59-year-olds to -0.5 among those aged 70 and older. For the $0-5$ measure of attention/calculation, women's deficit tends to decrease with increasing age, from -1.5 among 50- to 59-year-olds to -0.8 among those aged 70 and older. For the $0-1$ measure of language (copying a drawing), women's deficit varies little with increasing age, from -0.3 among 50- to 59-year-olds to -0.2 among those aged 70 and older. Women's and men's mean scores for immediate and delayed recall-namely, following a three-step command and also repeating a local proverb-do not differ significantly.

According to Table 2, there is - as expected - no variation in parental assets across men and women (because the respondent's sex is random). Most men (93.3\%) and women (91.7\%) had fathers with no schooling; roughly half of men $(51.5 \%)$ and women $(49.5 \%)$ lived at least five years of their childhood in a rural area; and men and women, on average, reported to have had an average to good family economic status in childhood (scores 3.4 and 3.5, respectively). Yet, compared with women, men had completed more schooling (4.1 vs. 1.2 grades), more often had worked (25.0\% vs. $7.8 \%)$, and less often were married before age $16(1.7 \%$ vs. $27.4 \%)$.

Regarding cognitive resources and constraints in adulthood, working at age 50 was more common for men $(94.4 \%)$ than women $(15.7 \%)$. Men also had a marginally higher average score for household standard of living than did women (10.6 vs. 9.7). Compared with men, women more often had experienced a divorce or widowhood (52.2\% vs. 21.7\%), reported a higher mean number of deceased sons $(0.8$ vs. 0.5$)$ and deceased daughters $(0.6$ 
Table 1. Distributions of Score for the Modified Mini-Mental Status Exam (M-MMSE) and Its Individual Items: Women and Men Aged 50 and Older in Two Districts in Ismailia, Egypt

\begin{tabular}{|c|c|c|c|c|c|c|}
\hline & \multicolumn{3}{|c|}{ Median $^{\mathrm{a}}$} & \multicolumn{2}{|c|}{ Mean $(95 \% \mathrm{CI})^{\mathrm{b}, \mathrm{c}}$} & \multirow{2}{*}{$\begin{array}{c}\text { Mean } \\
\text { Difference }^{b, c, c} \\
\text { W }-M\end{array}$} \\
\hline & Men & Women & $p$ & Men & Women & \\
\hline \multicolumn{7}{|l|}{ M-MMSE (0-20) } \\
\hline Total & 17.00 & 15.00 & $* * *$ & $\begin{array}{c}17.17 \\
(16.50,17.84)\end{array}$ & $\begin{array}{c}15.23 \\
(14.79,15.69)\end{array}$ & $-1.93^{* * *}$ \\
\hline $50-59$ years & 18.00 & 16.00 & $* * *$ & $\begin{array}{c}18.04 \\
(17.24,18.84)\end{array}$ & $\begin{array}{c}15.89 \\
(15.50,16.28)\end{array}$ & $-2.15^{* * *}$ \\
\hline 60-69 years & 17.00 & 15.00 & $* * *$ & $\begin{array}{c}16.91 \\
(16.58,17.24)\end{array}$ & $\begin{array}{c}14.98 \\
(14.49,15.47)\end{array}$ & $-1.93^{* * *}$ \\
\hline$\geq 70$ years & 16.00 & 14.00 & $* * *$ & $\begin{array}{c}15.19 \\
(14.77,15.68)\end{array}$ & $\begin{array}{c}13.43 \\
(12.23,14.64)\end{array}$ & $-1.75^{* *}$ \\
\hline \multicolumn{7}{|c|}{ Orientation } \\
\hline \multicolumn{7}{|c|}{ Know residence and day of week $(0-4)^{\mathrm{e}}$} \\
\hline Total & 4.00 & 4.00 & $* * *$ & $\begin{array}{c}3.93 \\
(3.89,3.97)\end{array}$ & $\begin{array}{c}3.72 \\
(3.66,3.79)\end{array}$ & $-0.21^{* * *}$ \\
\hline $50-59$ years & 4.00 & 4.00 & $* * *$ & $\begin{array}{c}3.99 \\
(3.96,4.01)\end{array}$ & $\begin{array}{c}3.83 \\
(3.77,3.89)\end{array}$ & $-0.16^{* * *}$ \\
\hline 60-69 years & 4.00 & 4.00 & $* * *$ & $\begin{array}{c}3.91 \\
(3.84,3.98)\end{array}$ & $\begin{array}{c}3.71 \\
(3.58,3.83)\end{array}$ & $-0.21^{* *}$ \\
\hline$\geq 70$ years & 4.00 & 4.00 & $* * *$ & $\begin{array}{c}3.82 \\
(3.74,3.90)\end{array}$ & $\begin{array}{c}3.36 \\
(3.12,3.60)\end{array}$ & $-0.46^{* *}$ \\
\hline \multicolumn{7}{|c|}{ Registration and Recall } \\
\hline \multicolumn{7}{|c|}{ Immediate recall of three words $(0-3)$} \\
\hline Total & 3.00 & 3.00 & & $\begin{array}{c}2.93 \\
(2.89,2.97)\end{array}$ & $\begin{array}{c}2.92 \\
(2.88,2.96)\end{array}$ & -0.01 \\
\hline $50-59$ years & 3.00 & 3.00 & & $\begin{array}{c}2.97 \\
(2.92,3.01)\end{array}$ & $\begin{array}{c}2.95 \\
(2.92,2.99)\end{array}$ & -0.01 \\
\hline 60-69 years & 3.00 & 3.00 & & $\begin{array}{c}2.92 \\
(2.85,2.99)\end{array}$ & $\begin{array}{c}2.93 \\
(2.85,3.02)\end{array}$ & 0.01 \\
\hline$\geq 70$ years & 3.00 & 3.00 & $\dagger$ & $\begin{array}{c}2.83 \\
(2.74,2.91)\end{array}$ & $\begin{array}{c}2.76 \\
(2.61,2.92)\end{array}$ & -0.06 \\
\hline \multicolumn{7}{|c|}{ Delayed recall of three words $(0-3)$} \\
\hline Total & 3.00 & 2.00 & ** & $\begin{array}{c}2.40 \\
(2.24,2.57)\end{array}$ & $\begin{array}{c}2.23 \\
(2.09,2.37)\end{array}$ & -0.17 \\
\hline $50-59$ years & 3.00 & 3.00 & $*$ & $\begin{array}{c}2.61 \\
(2.44,2.79)\end{array}$ & $\begin{array}{c}2.38 \\
(2.22,2.53)\end{array}$ & $-0.24^{*}$ \\
\hline 60-69 years & 3.00 & 2.00 & & $\begin{array}{c}2.28 \\
(2.08,2.47)\end{array}$ & $\begin{array}{c}2.17 \\
(1.99,2.35)\end{array}$ & -0.10 \\
\hline$\geq 70$ years & 2.00 & 2.00 & * & $\begin{array}{c}2.06 \\
(1.93,2.18)\end{array}$ & $\begin{array}{c}1.84 \\
(1.37,2.31)\end{array}$ & -0.22 \\
\hline
\end{tabular}




\begin{tabular}{|c|c|c|c|c|c|}
\hline \multicolumn{3}{|c|}{ Mediana } & \multicolumn{2}{|c|}{ Mean $(95 \% \mathrm{CI})^{\mathrm{b}, \mathrm{c}}$} & $\begin{array}{l}\text { Mean } \\
\text { Differenceb,c,d }\end{array}$ \\
\hline Men & Women & $p$ & Men & Women & $\mathrm{W}-\mathrm{M}$ \\
\hline
\end{tabular}

$\begin{aligned} & \text { Attention and Calculation } \\ & \text { Reverse recall of numbers (0-5) } \\ & \text { Total }\end{aligned}$

Language

Following a three-step command (0-3)

$\begin{array}{lccccc}\text { Total } & 3.00 & 3.00 & 2.92 & 2.94 & 0.02 \\ \text { 50-59 years } & 3.00 & 3.00 & (2.86,2.98) & (2.90,2.97) & \\ & & & 2.94 & 2.96 & 0.02 \\ \text { 60-69 years } & 3.00 & 3.00 & (2.86,3.02) & (2.91,3.01) & \\ & & & 2.94 & 2.96 & 0.01 \\ \geq 70 \text { years } & 3.00 & 3.00 & (2.87,3.01) & (2.89,3.02) & \\ & & & 2.83 & 2.82 & -0.01\end{array}$

Copying a drawing (proportion correct)

Total

$\begin{array}{lll}0.73 & 0.46 & -0.27^{* * *}\end{array}$

$(0.65,0.80) \quad(0.40,0.53)$

$50-59$ years

0.81

0.54

$-0.27^{* * *}$

$(0.71,0.90)$

$(0.46,0.62)$

60-69 years

0.74

0.44

$-0.30^{* * *}$

$(0.65,0.82)$

$(0.35,0.52)$

$\geq 70$ years
0.48
0.25

$-0.23^{* * *}$

$(0.42,0.53) \quad(0.20,0.30)$

Repeating a local proverb (proportion correct)

$\begin{array}{lccc}\text { Total } & 0.98 & 0.97 & -0.01 \\ & (0.97,1.00) & (0.96,0.98) & \\ 50-59 \text { years } & 1.00 & 0.97 & -0.03^{*} \\ \text { 60-69 years } & (1.00,1.00) & (0.95,0.99) & \\ & 0.98 & 0.99 & 0.01 \\ \geq 70 \text { years } & (0.95,1.00) & (0.97,1.01) & \\ & 0.94 & 0.93 & -0.01 \\ \end{array}$

${ }^{\mathrm{a}}$ Unweighted samples sizes are as follows: total $=995$ (466 men; 529 women); 50-59 years = 364 (159 men; 205 women); 60-69 years $=320$ (162 men; 158 women); and $\geq 70$ years $=311$ ( 145 men; 166 women).

${ }^{\mathrm{b}}$ Estimates adjusted for stratified sample design.

'Weighted samples sizes are as follows: total = 1,003 (500 men; 503 women); 50-59 years = 508 (245 men; 263 women); 60-69 years $=338$ ( 170 men; 169 women $)$; and $\geq 70$ years $=157$ ( 85 men; 72 women $)$.

${ }^{\mathrm{d}}$ These $p$ values are adjusted for the sample design.

${ }^{\mathrm{e}}$ Residence refers to village or city, district, and governorate in which the respondent is living.

${ }^{\dagger} p<.10 ;{ }^{*} p<.05,{ }^{* *} p<.01,{ }^{* * *} p<.001$ 
Table 2. Characteristics of Men and Women Aged 50 and Older in Two Districts in Ismailia, Egypt

Men

Childhood ( $\leq 15$ years) Cognitive Resources

and Constraints, $\mathbf{C}_{\mathbf{r}}$

Father's schooling (ref. $=$ none)

Any

Missing

Family economic status ${ }^{a}$

Rural residence for five or more years (ref. $=$ no)

Yes

Missing

Number of grades

Number of grades, squared

Worked before age 16 (ref. = no)

First married before age 16 (ref. = no)

Age at first marriage imputed

Childhood Health Status, $\mathbf{C}_{\mathbf{h}}$

Smoked before age 16 (ref. $=$ no)

Yes

Missing

Confined to bed for at least one month for a health problem $($ ref. $=$ no $)$

Yes

Missing

Any major child illness ${ }^{\mathrm{b}}$

Adult (aged 16 and older) Cognitive Resources

and Constraints, $\mathbf{A}_{\mathbf{r}}$

Household standard of living score ${ }^{c}$

Working at age $50($ ref. $=$ no $)$

Number of children ever born

Number of deceased sons

Number of deceased daughters

Ever divorced or widowed

Number of living brothers

Number of living sisters

Lived alone five years before interview

Relationship to (former) spouse (ref. = nonrelative)

Cousin

Other relative

$\begin{array}{rr}93.3 & 91.7 \\ 5.9 & 6.1 \\ 0.8 & 2.2\end{array}$

$3.44(3.36,3.51)$

$3.51(3.45,3.58)$

47.2

49.8

51.5

49.5

1.3

0.7

$4.08(2.91,5.26)$

$1.21(0.90,1.52)$

$42.46(23.39,61.52)$

$8.63(4.65,12.61)$

25.0

1.7

8.2

27.4

19.1

69.1

97.1

29.0

0.9

1.9

2.1

92.8

88.0

3.4

5.0

3.8

7.0

40.3

38.4

$10.56(9.85,11.28)$

$9.73(9.08,10.38)$

94.4

15.7

$5.96(5.43,6.48)$

$6.30(5.67,6.92)$

$0.54(0.42,0.65)$

$0.78(0.61,0.95)$

$0.45(0.38,0.52)$

21.7

$0.63(0.52,0.73)$

52.2

$1.77(1.51,2.03)$

$1.86(1.67,2.05)$

$1.77(1.61,1.93)$

$1.72(1.52,1.93)$

2.4

8.4

54.6

53.9

35.6

36.4

9.8 
(Table 2, continued)

\begin{tabular}{|c|c|c|c|}
\hline & Men & Women & $p$ \\
\hline \multicolumn{4}{|l|}{ Adult Health Status (self-reported doctor-diagnosed), $\mathbf{A}_{\mathbf{h}}$} \\
\hline Smoked at age 16 or later $($ ref. $=$ no $)$ & 19.0 & 87.2 & *** \\
\hline Yes & 80.5 & 11.1 & \\
\hline Missing & 0.5 & 1.7 & \\
\hline Diabetes $($ ref. $=$ no $)$ & 13.4 & 18.8 & $\dagger$ \\
\hline Heart disease (ref. $=$ no) & 6.0 & 9.5 & \\
\hline High blood pressure (ref. = no) & 72.2 & 53.0 & $* * *$ \\
\hline Yes & 26.5 & 46.3 & \\
\hline Missing & 1.4 & 0.7 & \\
\hline Stroke (ref. = no) & 5.5 & 3.5 & \\
\hline Score for health-condition-specific medications taken ${ }^{\mathrm{d}}$ & $0.85(0.64,1.07)$ & $1.32(1.16,1.47)$ & $* * *$ \\
\hline \multicolumn{4}{|l|}{ Other Controls, $\mathbf{X}$} \\
\hline Age in years & $1.20(58.05,64.34)$ & $60.62(58.02,63.20)$ & \\
\hline Rural residence (ref. = urban) & 27.6 & 31.3 & \\
\hline \multicolumn{4}{|c|}{$\begin{array}{l}\text { Notes: Weighted sample sizes are } 500 \text { for men and } 503 \text { for women. Unweighted sample sizes are } 466 \text { for men and } 529 \text { for } \\
\text { women. }\end{array}$} \\
\hline \multicolumn{4}{|c|}{${ }^{a}$ Self-rated as very poor (1), poor (2), average (3), good (4), very good (5). } \\
\hline \multicolumn{4}{|c|}{$\begin{array}{l}\text { bilharizia, anemia, nephritis, hepatitis, measles, tuberculosis, rheumatic fever, asthma, chronic bronchitis, polio, mumps, } \\
\text { meningitis, and other. }\end{array}$} \\
\hline \multicolumn{4}{|c|}{$\begin{array}{l}\text { 'Sum of } 17 \text { assets/amenities: finished floor, water piped into residence or yard, flushing toilet, radio, television, video, tele- } \\
\text { phone, cell phone, fan, heater, refrigerator, washer, bicycle, car, tap, soap, and sink. }\end{array}$} \\
\hline \multicolumn{4}{|c|}{${ }^{\mathrm{d}}$ Range from did not take (0) to took continuously last year (8). } \\
\hline${ }^{\dagger} p<.10 ;{ }^{*} p<.05 ;{ }^{* *} p<.01 ;{ }^{* * *} p<.001$ (adjusted for the sa & imple design) & & \\
\hline
\end{tabular}

vs. 0.5 ), and more often were living alone five years before the interview ( $8.4 \%$ vs. $2.4 \%$ ). The total number of children ever born, number of living brothers, number of living sisters, and relational status to the first spouse, however, were similar for women and men.

Regarding measures of health status and other controls, estimates for childhood do not differ for men and women. Most men (92.8\%) and women $(88.0 \%)$ reported that they had not been confined to bed as a child for at least one month for a health-related reason, but slightly more than one-third of men $(40.3 \%)$ and women $(38.4 \%)$ reported that they had had at least one major illness in childhood. Compared with women $(0.9 \%)$, men more often $(29.0 \%)$ reported to have smoked before age 16 . Male-female gaps in health status in adulthood are more apparent. Women reported doctor-diagnosed diabetes $(18.8 \%$ vs. $13.4 \%)$ and high blood pressure (46.3\% vs. $26.5 \%)$ at least marginally more often, and women had a higher mean score for the use of medications in the prior year to manage diabetes, heart disease, high blood pressure, and/or a prior stroke (1.3 vs. 0.9). Compared with women $(11.1 \%)$, however, men $(80.5 \%)$ more often had smoked after age 15 . The relative frequencies of reported, doctor-diagnosed heart disease and stroke, as well as the mean ages (61.2 vs. 60.6) and percentages living in the rural district (27.6 vs. 31.1), were similar for men and women.

Table 3 shows the full multivariate models for men and women separately (Panel A) as well as the results of the Oaxaca-Blinder decomposition (Panel B). Adjusting for measures of health status and other controls (Panel A), adjusted Wald $F$ statistics show that for 
women and men, variables measuring cognitive resources and constraints in childhood are jointly significantly associated with the M-MMSE score. Of these measures in childhood, the number of grades of schooling is associated with the M-MMSE score for men and women. An increase of one grade of schooling among men is associated with a diminishing increment in the M-MMSE score, as a result of the significant, negative squared term for grades of schooling. Among women, an increase of one grade of schooling is associated with a linear increment of 0.24 points in the M-MMSE score. Among men only, working before age 16 is associated with a 0.27 decrement in the M-MMSE score, and a one-point increase in family economic status in childhood is associated with a 0.09 decrement in the M-MMSE score.

Controlling for health status and other variables, adjusted Wald $F$ statistics show that for women and men, variables measuring cognitive resources and constraints in adulthood are jointly associated with the M-MMSE score. Among these measures, the score for household standard of living is positively associated with the M-MMSE score for men and women. A one-point increment in the household standard-of-living score is associated with increments of 0.14 for men and 0.10 for women in the M-MMSE score. Otherwise, for women, the number of living sisters is positively associated with the M-MMSE score, and living alone five years before the interview is negatively associated with the M-MMSE score.

Regarding the measures of health status and other controls, age is strongly and negatively associated with the M-MMSE score for women and men. Otherwise, no measures of health status in childhood and adulthood are significantly associated with the M-MMSE score in the adjusted model for men, and few such measures have significant adjusted associations in the model for women. Being confined to bed for at least one month for a health-related reason in childhood is positively associated with the M-MMSE score, and having experienced a stroke is negatively associated with the M-MMSE score.

The last column in Table 3 provides the $p$ values associated with adjusted Wald $F$ statistics for the significance of differences in estimated coefficients, individually and as sets, across models of the M-MMSE score for men and women. Together, the estimated coefficients differ significantly across models. As subsets, the estimated coefficients for measures of cognitive resources and constraints in childhood, health status in childhood, health status in adulthood, and other controls do not jointly differ across models; however, the estimated coefficients for measures of cognitive resources and constraints in adulthood do jointly differ. Evaluated separately, two of the coefficients in this set differ marginally across models $(p<.10)$ : being married to a blood relative is negatively associated with the M-MMSE score for men and positively associated with it for women, whereas being divorced or widowed is positively associated with the M-MMSE score for men and negatively associated with it for women.

Panel B of Table 3 shows the results of the Oaxaca-Blinder decomposition. This panel presents the mean M-MMSE scores for men (17.17) and women (15.24), the difference in these mean scores (1.93), and the amounts and percentages of this difference that are attributable to gender gaps in mean characteristics and in their effects. More than $83 \%$ of the difference in men's and women's mean M-MMSE scores is attributable to differences in their mean characteristics $(100 \times 1.61 / 1.93)$. The remaining $17 \%$ of this difference $(100 \times 0.32$ $/ 1.93$ ) is attributable to differences across gender in the effects of these characteristics.

Given the general lack of gender-differentiated covariate effects on the M-MMSE score, and the significant effects of schooling and adult household standard of living for men and women, Figure 2 summarizes the effect on the gender gap in the M-MMSE score of accounting for (1) no covariates, (2) all covariates except schooling and adult household standard of living, (3) all covariates except schooling, (4) all covariates except adult household standard of living, and (5) all covariates. These results reveal the importance of schooling for reducing the gender gap in overall later-life cognitive functioning. The inclusion of schooling in adjusted models significantly reduces the gender gap in the 
Table 3. Adjusted OLS Regressions of the M-MMSE on Cognitive Resources and Constraints in Childhood and Adulthood: Men and Women Aged 50 and Older in Two Districts in Ismailia, Egypt

\begin{tabular}{|c|c|c|c|}
\hline & $\begin{array}{c}\text { Men } \\
\boldsymbol{\beta}_{\mathrm{M}}\end{array}$ & $\begin{array}{c}\text { Women } \\
\boldsymbol{\beta}_{\mathrm{w}}\end{array}$ & $\begin{array}{c}\boldsymbol{\beta}_{\mathrm{M}}=\boldsymbol{\beta}_{\mathrm{W}} \\
p(>\mathrm{F})\end{array}$ \\
\hline \multicolumn{4}{|l|}{ Panel A } \\
\hline Constant & $21.358^{* * *}$ & $17.844^{* * *}$ & \\
\hline $\begin{array}{l}\text { Child Cognitive Resources and Constraints, } \mathbf{C}_{\mathbf{r}} \\
\text { Father's schooling (ref. = none) }\end{array}$ & & & $\mathrm{ns}$ \\
\hline Any & 0.331 & 0.485 & \\
\hline Missing & 0.374 & 1.325 & \\
\hline Family economic status ${ }^{a}$ & $-0.088^{*}$ & 0.140 & \\
\hline \multicolumn{4}{|l|}{ Rural residence for five or more years $(\mathrm{ref} .=\mathrm{no})$} \\
\hline Yes & -0.708 & -0.430 & \\
\hline Missing & -0.616 & 1.791 & \\
\hline Number of grades of schooling & $0.234^{*}$ & $0.237^{* *}$ & \\
\hline Number of grades of schooling, squared & $-0.009^{*}$ & -0.002 & \\
\hline Worked before age 16 (ref. = no) & $-0.268^{*}$ & -0.033 & \\
\hline First married before age $16($ ref. $=$ no $)$ & 0.540 & -0.263 & \\
\hline Age at first marriage imputed & -0.976 & $-0.815^{*}$ & \\
\hline Childhood Health Status, $\mathbf{C}_{\mathbf{h}}$ & & & ns \\
\hline \multicolumn{4}{|l|}{ Smoked before age 16 (ref. = no) } \\
\hline Yes & -0.432 & -0.527 & \\
\hline Missing & 0.775 & -2.599 & $\dagger$ \\
\hline \multicolumn{4}{|c|}{$\begin{array}{l}\text { Confined to bed for at least one month for a health problem } \\
\text { (ref. = no) }\end{array}$} \\
\hline Yes & 0.711 & $0.945^{* *}$ & \\
\hline Missing & -0.276 & -0.867 & \\
\hline Any major child illness ${ }^{\mathrm{b}}$ & 0.038 & 0.350 & \\
\hline $\begin{array}{l}\text { Adult Cognitive Resources and Constraints, } \mathbf{A}_{\mathbf{r}} \\
\text { Household standard of living score }\end{array}$ & $0.138^{*}$ & $0.099^{* *}$ & * \\
\hline Working at age 50 years $($ ref. $=$ no $)$ & 0.793 & -0.100 & \\
\hline Number of children ever born & -0.094 & 0.041 & \\
\hline Number of deceased sons & 0.253 & -0.021 & \\
\hline Number of deceased daughters & -0.209 & -0.120 & \\
\hline Ever divorced or widowed & 0.439 & -0.183 & $\dagger$ \\
\hline \multicolumn{4}{|c|}{ Relationship to (former) spouse (ref. = nonrelative) } \\
\hline Cousin & -0.143 & -0.138 & \\
\hline Other relative & -1.177 & 0.307 & $\dagger$ \\
\hline Number of living brothers & 0.034 & 0.020 & \\
\hline Number of living sisters & 0.057 & $0.181^{*}$ & \\
\hline Lived alone for five years before interview & 1.073 & $-0.781^{*}$ & \\
\hline
\end{tabular}




\begin{tabular}{|c|c|c|c|}
\hline & $\begin{array}{c}\text { Men } \\
\boldsymbol{\beta}_{\mathrm{M}}\end{array}$ & $\begin{array}{c}\text { Women } \\
\boldsymbol{\beta}_{\mathrm{w}}\end{array}$ & $\begin{array}{c}\boldsymbol{\beta}_{\mathrm{M}}=\boldsymbol{\beta}_{\mathrm{W}} \\
p(>\mathrm{F})\end{array}$ \\
\hline \multicolumn{4}{|l|}{ Panel A (cont.) } \\
\hline Adult Health Status, $\mathbf{A}_{\mathbf{h}}$ & & & $\mathrm{ns}$ \\
\hline \multicolumn{4}{|l|}{ Smoked at age 16 or later $($ ref. $=$ no $)$} \\
\hline Yes & -0.085 & 0.084 & \\
\hline Missing & -1.275 & 2.409 & $\dagger$ \\
\hline Diabetes, reported doctor-diagnosed $($ ref. $=$ no $)$ & -0.030 & 0.230 & \\
\hline Heart disease, reported doctor-diagnosed $($ ref. $=$ no $)$ & -0.637 & 0.708 & $\dagger$ \\
\hline \multicolumn{4}{|l|}{ High blood pressure, reported doctor-diagnosed $($ ref. $=$ no $)$} \\
\hline Yes & -0.151 & -0.142 & \\
\hline Missing & -0.334 & 2.648 & $\dagger$ \\
\hline Stroke $($ ref. $=$ no $)$ & -1.065 & $-2.034^{* *}$ & \\
\hline Score for health-condition-specific medication taken ${ }^{\mathrm{d}}$ & 0.040 & 0.039 & \\
\hline Other Controls, $\mathbf{X}$ & & & $\mathrm{ns}$ \\
\hline Age in years & $-0.091^{* * *}$ & $-0.071^{* * *}$ & \\
\hline Rural residence (ref. = urban) & 0.120 & -0.410 & \\
\hline Total Model & & & * \\
\hline$R^{2}$ & 0.29 & 0.30 & \\
\hline \multicolumn{4}{|c|}{ Joint Adjusted Wald $F$ Tests for the Significance of Model Coefficients } \\
\hline$F_{(10,12)}$ for $\mathbf{C}_{\mathbf{r}}$ & $3.03^{*}$ & $20.77^{* * *}$ & \\
\hline$F_{(5,17)}$ for $\mathbf{C}_{\mathbf{h}}$ & 0.62 & $5.43^{* *}$ & \\
\hline$F_{(11,11)}$ for $\mathbf{A}_{\mathbf{r}}$ & $2.16^{\dagger}$ & $5.09^{* *}$ & \\
\hline$F_{(8,14)}$ for $\mathbf{A}_{\mathbf{h}}$ & 0.46 & $8.07^{* * *}$ & \\
\hline$F_{(2,20)}$ for $\mathbf{X}$ & $10.18^{* * *}$ & $7.23^{* *}$ & \\
\hline \multicolumn{4}{|l|}{ Panel B } \\
\hline \multicolumn{4}{|l|}{ Oaxaca-Blinder Decomposition } \\
\hline High prediction: men & $17.17^{* * *}$ & & \\
\hline Low prediction: women & $15.24^{* * *}$ & & \\
\hline Difference in predictions, men - women & $1.93^{* * *}$ & & \\
\hline $\begin{array}{l}\text { Amount (and \%) of difference due to differences in } \\
\text { mean characteristics }\end{array}$ & $1.61^{* * *}$ & $(83.3)$ & \\
\hline $\begin{array}{l}\text { Amount (and \%) of differences due to different effec } \\
\text { mean characteristics }\end{array}$ & $0.32^{* * *}$ & $(16.7)$ & \\
\hline
\end{tabular}

Note: Unweighted sample sizes are 466 for men and 529 for women. Weighted sample sizes are 500 for men and 503 for women.

${ }^{a}$ Self-rated as very poor (1), poor (2), average (3), good (4), or very good (5).

${ }^{\mathrm{b}}$ Bilharizia, anemia, nephritis, hepatitis, measles, tuberculosis, rheumatic fever, asthma, chronic bronchitis, polio, mumps, meningitis, and other.

'Sum of 17 assets/amenities: finished floor, water piped into residence or yard, flushing toilet, radio, television, video, telephone, cell phone, fan, heater, refrigerator, washer, bicycle, car, tap, soap, and sink.

${ }^{\mathrm{d}}$ Range from did not take (0) to took continuously last year (8).

${ }^{\dagger} p<.10 ;{ }^{*} p<.05 ;{ }^{* *} p<.01 ;{ }^{* * *} p<.001$ (adjusted for the sample design) 
Figure 2. Gender Gap (women - men) in the M-MMSE Score for Adults Aged 50 and Older: Two Districts in Ismailia, Egypt

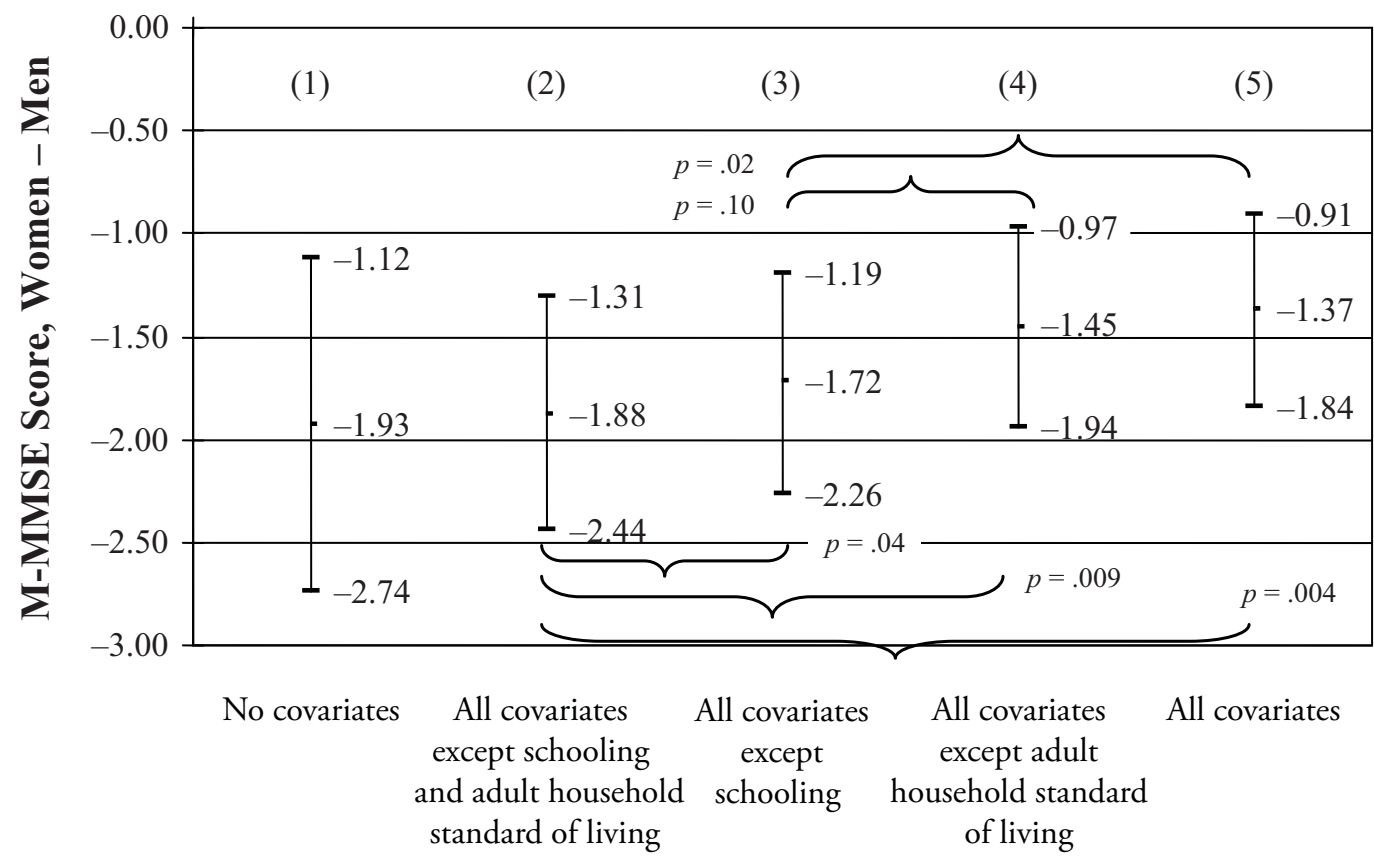

Note: Nonsignificant differences in coefficients are not shown.

M-MMSE by $18 \%$ (e.g., from -1.72 to -1.37 ); the inclusion of adult household standard of living in adjusted models reduces this gender gap (nonsignificantly) by $4 \%$ (e.g., from -1.45 to -1.37$)$.

\section{DISCUSSION}

This article evaluates, in a poor and gender-stratified setting, whether and to what extent older women have poorer cognitive functioning than do older men. It also assesses to what extent any such deficit results from gender gaps in the cognitive resources that accrue across the life course, as well as from any gender-differentiated effects of these resources. This analysis is the first to use community-based data to evaluate these questions in a poor setting, such as Egypt, where a female disadvantage in opportunities across the life course is known but where its potential consequences for gender gaps in later-life cognitive functioning are unknown.

As expected (Hypothesis 1), older women in this sample have significantly poorer overall cognitive functioning than older men. This gap corroborates those found in Taiwan (Hsu 2005) and China (Zhang 2006), which historically have been highly gender stratified. Further research in more and less gender-stratified settings is needed to determine the pattern of the gender gap across contexts.

Also as expected (Hypothesis 2), and consistent with the framework adapted from Richards and Deary (2005), cognitive resources in both childhood and adulthood are associated with cognitive functioning in later life. The respondent's schooling and household stand of living at interview are significant and positive determinants of later-life cognitive functioning for women and men. These two resources also account for a large share of the residual gender gap in cognitive functioning ( $22 \%$; Hypothesis $3 \mathrm{a})$, and schooling accounts for a larger 
share of this gap (18\% vs. $4 \%$ ). These findings, although not causal, corroborate the idea that reserve can be augmented across the life course (Bornstein et al. 2006; Richards and Deary 2005).

Comparisons across models of the overall M-MMSE scores for men and women reveal few significant differences in the estimated coefficients (Hypothesis 3b). Results from the Oaxaca-Blinder decomposition confirm that differences in mean childhood, adult, and control attributes account for about $83 \%$ of the gender gap in cognitive functioning. Two potential policy implications emerge from these findings. First, reducing gaps in the cognitive resources that men and women accrue - and especially formal schooling - may reduce gaps in their overall later-life cognitive functioning. Second, efforts to alter qualitative differences in men's and women's cognitive resources may only modestly reduce gaps in overall cognitive functioning in this setting. Decompositions of gender gaps in subdomains of cognitive functioning (e.g., orientation, registration, and language) would clarify the reasons for gaps in overall functioning, and research in other poor, gender-stratified settings is needed to confirm the scope of these findings. Analyses exploring interactions of age and cognitive resources may elucidate the determinants of cognitive decline.

\section{REFERENCES}

Albert, M.S. 1995. "How Does Education Affect Cognitive Function?" Annals of Epidemiology $5: 76-8$.

Alderman, H., J.R. Behrman, D.R. Ross, and R. Sabot. 1996. "Decomposing the Gender Gap in Cognitive Skills in a Poor Rural Economy." Journal of Human Resources 31:229-54.

Bornstein, A.R., C.I. Copenhaver, and J.A. Mortimer. 2006. "Early-Life Risk Factors for Alzheimer Disease." Alzheimer Disease and Associated Disorders 20(1):63-72.

Breteler, M.M., J. J. Claus, D.E. Grobbee, and A. Hofman. 1994. "Cardiovascular Disease and Distribution of Cognitive Function in Elderly People: The Rotterdam Study." British Medical Journal 308:1604-608.

Cagney, K.A. and D.S. Lauderdale. 2002. "Education, Wealth, and Cognitive Function in Later Life." Journals of Gerontology: Psychological Sciences 57B(2):163-72.

Cerhan, J.R., A.R. Folsom, J.A. Mortimer, E. Shahar, D.S. Knopman, P.G. McGovern, M.A. Hays, L.D. Crum, and G. Heiss. 1998. "Correlates of Cognitive Function in Middle-Aged Adults. Atherosclerosis Risk in Communities (ARIC) Study Investigators." Gerontology 44:95-105.

Cook, J.R. and L.A. Stefanski. 1994. "Simulation Extrapolation Estimation in Parametric Measurement Error Models." Journal of the American Statistical Association 89:1314-28.

Elhan, A.H., S. Kutlay, A.A. Kucukdeveci, C. Cotuk, G. Ozturk, L. Tesio, and A. Tennant. 2005. "Psychometric Properties of the Mini-Mental State Examination in Patients With Acquired Brain Injury in Turkey." Journal of Rehabilitative Medicine 37:306-11.

El-Zanaty, F., E.M. Hussein, G.A. Shawky, A.A. Way, and S. Kishor. 1996. Egypt Demographic and Health Survey 1995. Calverton, MD: National Population Council [Egypt], Macro International, Inc.

Escobar J., A. Burnam, M. Karno, A. Forsythe, J. Landsverk, and J.M. Golding. 1986. "Use of the Mini-Mental State Examination (MMSE) in a Community Population of Mixed Ethnicity." Journal of Nervous and Mental Disorders 174:607-13.

Everson-Rose, S.A., C.F. Mendes de Leon, J.L. Bienias, R.S. Wilson, and D.A. Evans. 2003. "Early Life Conditions and Cognitive Functioning in Later Life." American Journal of Epidemiology 158:1083-89.

Farrag, A.K., E.M. Khedr, H. Abdel-Aleem, and T.A. Rageh. 2002. "Effect of Surgical Menopause on Cognitive Functions." Dementia and Geriatric Cognitive Disorder 13:193-98.

Galal, O.M. 2002. "The Nutrition Transition in Egypt: Obesity, Undernutrition and the Food Consumption Context." Public Health Nutrition 5(1A):141-48.

Herman, W.H., M.A. Ali, R.E. Aubert, M.M. Engelgau, S.J. Kenny, E.W. Gunter, A.M. Malarcher, R.J. Brechner, S.F. Wetterhall, F. DeStefano, T.J. Thompson, P.J. Smith, A. Badran, E.S. Sous, 
M. Habib, M. Hegazy, S. abd el Shakour, A.S. Ibrahim, and A. el Moneim el Behairy. 1995. "Diabetes Mellitus in Egypt: Risk Factors and Prevalence." Diabetes Medicine 12:1126-31.

Hill, K. and D. Upchurch. 1995. "Gender Differences in Child Health: Evidence From the Demographic and Health Survey." Population and Development Review 21:127-51.

Hoodfar, H. 1997. Between Marriage and the Market: Intimate Politics and Survival in Cairo. Berkeley: University of California Press.

Hsu, H.C. 2005. "Gender Disparity of Successful Aging in Taiwan." Women and Health 42(1): $1-21$.

Huber, P.J. 1967. "The Behavior of Maximum Likelihood Estimates Under Nonstandard Conditions." Pp. 221-23 in Proceedings of the Fifth Berkeley Symposium on Mathematical Statistics and Probability, Vol. 1. Berkeley, CA: University of California Press.

Ibrahim, M.M., L.J. Appel, H.H. Rizk, S. Helmy, J. Mosley, Z. Ashour, W. El-Aroussy, E. Roccella, and P. Whelton. 2001. "Cardiovascular Risk Factors in Normotensive and Hypertensive Egyptians." Journal of Hypertension 19:1933-40.

Jann, B. 2005. Standard Errors for the Blinder-Oaxaca Decomposition. Available online at http:// repec.org/dsug2005/oaxaca_se_handout.pdf.

Kabir, Z.N. and A. Herlitz. 2000. "The Bangla Adaptation of Mini-Mental State Examination (BAMSE): An Instrument to Assess Cognitive Function in Illiterate and Literate Individuals." International Journal of Geriatric Psychiatry 15:441-50.

Kannel, W.B. 2002. "The Framingham Study: Historical Insight on the Impact of Cardiovascular Risk Factors in Men Versus Women.” Journal of Gender Specific Medicine 5(2):27-37.

King, E.M. and A.D. Mason. 2001. Engendering Development-Through Gender Equality in Rights, Resources, and Voice. New York: Oxford University Press, and Washington, DC: The World Bank.

Kuusisto, J., K. Koivisto, L. Mykkanen, E.L. Helkala, M. Vanhanen, T. Hanninen, K. Pyorala, P. Riekkinen, and M. Laakso. 1993. "Essential Hypertension and Cognitive Function: The Role of Hyperinsulinemia." Hypertension 22:771-79.

Lebrun, C.E., Y.T. van der Schouw, F.H. de Jong, H.A. Pols, D.E. Grobbee, and S.W. Lamberts. 2005. "Endogenous Oestrogens Are Related to Cognition in Healthy Elderly Women." Clinical Endocrinology (Oxford) 63(1):50-55.

Lloyd, C.B., ed., and National Research Council/Institute of Medicine (NRC/IOM) panel on Transitions to Adulthood in Developing Countries. 2005. Growing Up Global: The Changing Transitions to Adulthood in Developing Countries. Washington, DC: National Academies Press.

Luo, Y. and L.J. Waite. 2005. "The Impact of Childhood and Adult SES on Physical, Mental, and Cognitive Well-being in Later Life." Journal of Gerontology B: Psychological Sciences and Social Sciences 60:S93-S101.

Manly, J.J., N. Schupf, M.-X. Tang, and Y. Stern. 2005. "Cognitive Decline and Literacy Among Ethnically Diverse Elders.” Journal of Geriatric Psychiatry 18:213-17.

Neumark, D. 1988. "Employers' Discriminatory Behavior and the Estimation of Wage Discrimination." Journal of Human Resources 23:279-95.

Oaxaca, R.L. and M.R. Ransom. 1994. "On Discrimination and the Decomposition of Wage Differentials." Journal of Econometrics 61:5-21.

Palloni, A. n.d. Protocol of the Multicenter Study: Health, Well-being, and Aging in Latin American and the Caribbean. Washington, DC: Pan American Health Organization.

Park, R.M., P.A. Schulte, J.D. Bowman, J.T. Walker, S.C. Bondy, M.G. Yost, J.A. Touchstone, and M. Dosemeci. 2005. "Potential Occupational Risks for Neurodegenerative Diseases." American Journal of Industrial Medicine 48:63-77.

Perls, T.T., J.N. Morris, W.L. Ooi, and L.A. Lipsitz. 1993. "The Relationship Between Age, Gender, and Cognitive Performance in the Very Old: The Effect of Selective Survival." Journal of the American Geriatric Society 41:1193-201.

Rennemark, M. and B. Hagberg. 1999. "Gender Specific Associations Between Social Network and Health Behavior in Old Age." Aging and Mental Health 3:320-27. 
Reynolds, C.A., A. Fiske, L. Fratiglioni, N.L. Pedersen, and M. Gatz. 2006. "Heritability of an AgeDependent Categorical Phenotype: Cognitive Dysfunction." Twin Research and Human Genetics 9(1):17-23.

Richards, M. and I.J. Deary. 2005. "A Life Course Approach to Cognitive Reserve: A Model for Cognitive Aging and Development." Annals of Neurology 58:617-22.

Richards, M., M.J. Jarvis, N. Thompson, and M.E.J. Wadsworth. 2003. "Cigarette Smoking and Cognitive Decline in Midlife: Evidence From a Prospective Birth Cohort Study." American Journal of Public Health 93:994-98.

Richards, M. and A. Sacker. 2003. "Lifetime Antecedents of Cognitive Reserve." Journal of Clinical and Experimental Neuropsychology 25:614-24.

Rosenzweig, M. and T.P. Schultz. 1982. "Market Opportunities, Genetic Endowments, and Intrafamily Resource Distribution: Child Survival in Rural India." American Economic Review 72:803-15.

Scarmeas, N. and Y. Stern. 2003. "Cognitive Reserve and Lifestyle." Journal of Clinical and Experimental Neuropsychology 25:625-33.

Schaie, K.W. 1994. "The Course of Adult Intellectual Development." American Psychologist 49:304-13.

Stern, Y., G.E. Alexander, I. Prohovnik, and R. Mayeux, 1992. "Inverse Relationship Between Education and Parietotemporal Perfusion Deficit in Alzheimer's Disease." Annals of Neurology $32: 371-75$.

Turrell, G., J.W. Lynch, G.A. Kaplan, S.A. Everson, E.L. Helkala, J. Kauhanen, and J.T. Salonen. 2002. "Socioeconomic Position Across the Life Course and Cognitive Function in Late Middle Age." Journals of Gerontology 57B(1):S43-S51.

United Nations, Population Division, Department of Economic and Social Affairs. 2007. World Population Prospects: The 2006 Revision. Available online at http://esa.un.org/unpp.

- 2007. World Urbanization Prospects: The 2007 Revision. Available online at http://esa .un.org/unpp.

United Nations Development Programme [UNDP] and Institute for National Planning [INP]. 2003. Egypt Human Development Report 2002-2003. Cairo: UNDP and INP.

United Nations Development Program [UNDP] Regional Bureau for Arab States. 2002. Arab Human Development Report: Creating Opportunities for Future Generations. New York: United Nations.

White, H. 1980. "A Heteroskedasticity-Consistent Covariance Matrix Estimator and a Direct Test for Heteroskedasticity." Econometrica 48:817-30.

Wilson, R.S., P.A. Scherr, J.L. Bienias, C.F. Mendes de Leon, S.A. Everson-Rose, D.A. Bennett, and D.A. Evans. 2005. "Socioeconomic Characteristics in the Community in Childhood and Cognition in Old Age." Experimental Aging Research 31:393-407.

World Bank Group. 2002. Genderstats: Database of Gender Statistics. Available online at http:// genderstats.worldbank.org/home.asp.

World Health Organization [WHO] 2007. Revised Global Burden of Disease (GBD) 2002 Estimates. Available online at http://www.who.int/healthinfo/bodgbd2002revised/en/index.html.

Yount, K.M. 2001. "Excess Mortality of Girls in the Middle East in the 1970s and 1980s: Patterns, Correlates, and Gaps in Research." Population Studies 55:291-308.

Yount, K.M. and E. Agree. 2005. "Differences in Disability Between Older Women and Men in Egypt and Tunisia." Demography 42:169-87.

Yount, K.M. and Z. Khadr. 2006. "A Biosocial Model of Medication Use Among Older Adults in Ismailia, Egypt.” Journal of Biosocial Science 38:577-603.

Yount, K.M. and A. Sibai. Forthcoming. "The Demography of Aging in Arab Countries." In International Handbook of the Demography of Aging, edited by P. Uhlenberg. Dordrecht, The Netherlands: Springer.

Zhang, M.Y., R. Katzman, D. Salmon, H. Jin, G.J. Cai, Z.Y. Wang, G.Y. Qu, I. Grant, E. Yu, P. Levy, M.R. Klauber, and W.T. Liu. 1990. "The Prevalence of Dementia and Alzheimer's Disease in Shanghai, China: Impact of Age, Gender, and Education." Annals of Neurology 27:428-37. 
Zhang, Z. 2006. "Gender Differentials in Cognitive Impairment and Decline of the Oldest Old in China." Journals of Gerontology: Social Sciences 61B(2):S107-15.

Zhou, D.F., C.S. Wu, H. Qi, J.H. Fan, X.D. Sun, P. Como, Y.L. Qiao, L. Zhang, and K. Kieburtz. 2006. "Prevalence of Dementia in Rural China: Impact of Age, Gender, and Education." Acta Neurologica Scandinavica 114:273-80. 